J. Environ. Sci.

Institute of Environmental Studies and Research - Ain Shams University

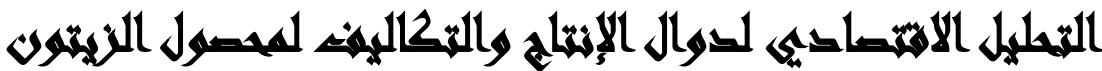

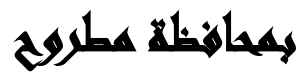

[r]

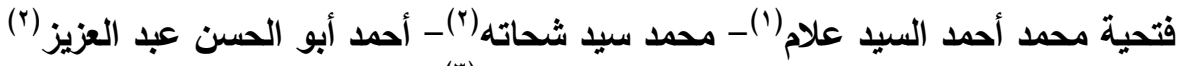

محمد محمود سامي (r) معائ)

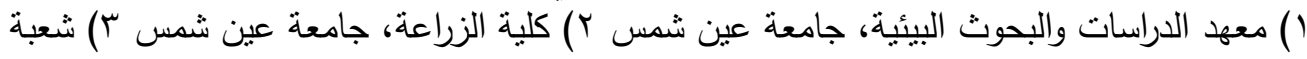

الدراسات الاقتصادية، مركز بحوث الصحراء الصنة الصعة

\section{المستخلتص}

تمثلت مشكلة البحث في محدودية الموارد المائية مع تتامي الاحتباجات المائية في الزراعة، لذا استهدف

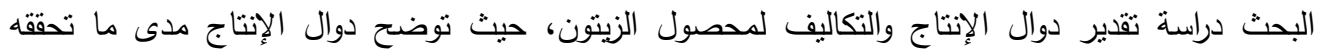

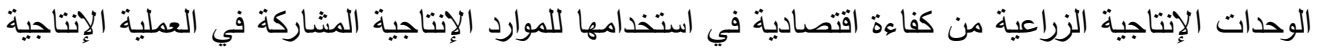

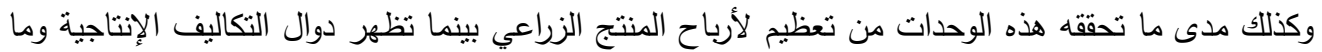

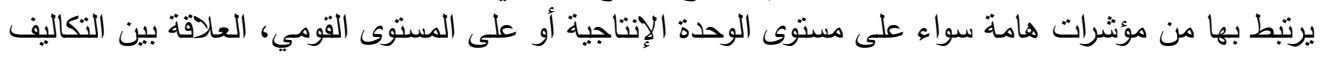

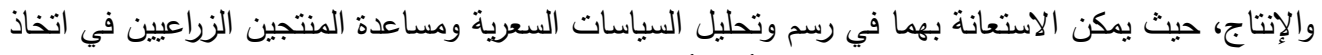

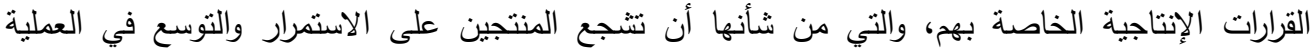

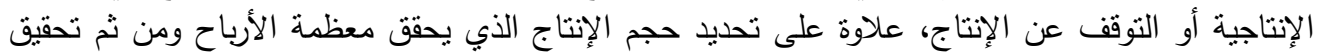
الكفاءة الاقتصادية من استخدام العناصر الإنتاجية.

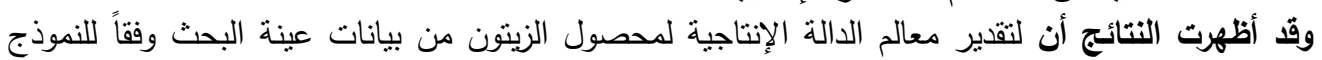

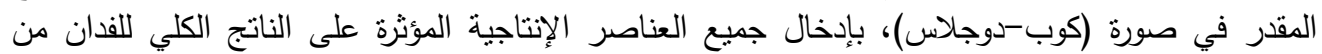

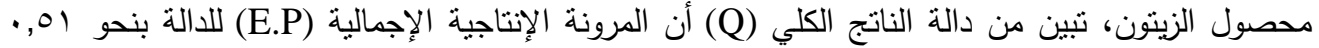

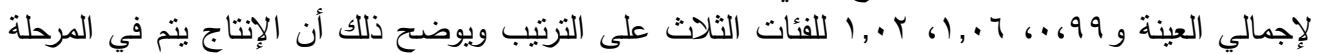

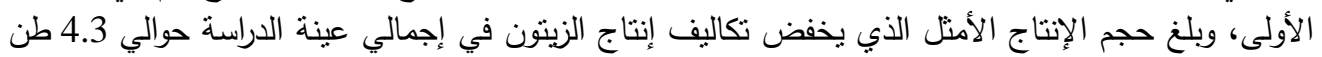

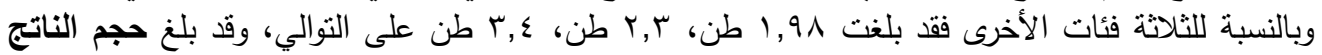

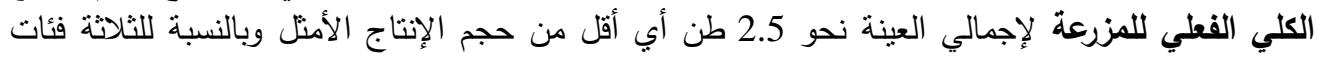

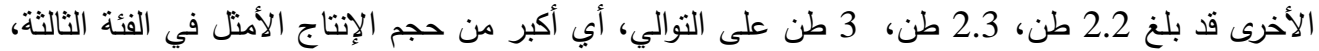

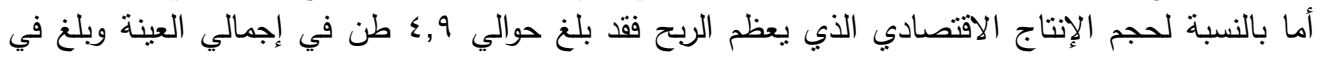

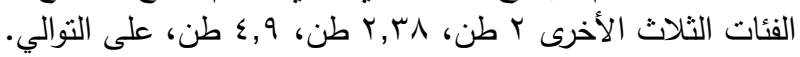

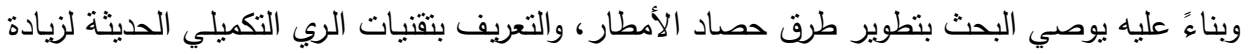
كفاءتها، والتوعية بأهمية عمليات الحرث لزيادة نفاذية التربة مما يجعلها قادرة على استيعاب أكبر قدر من مياه التياه 
الأمطار وتخزينها في طبقات تحت سطح التربة حتى تستفيد منها الأثـجار خـال موسم النمو، والاهتمام

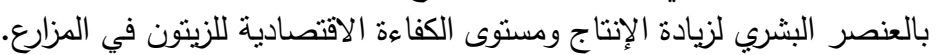

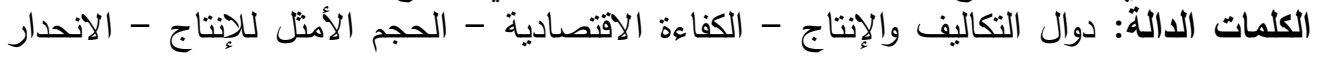
المتعدد المرحلي.

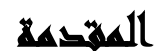

يعتبر الزيتون من محاصيل الفاكهة الهامة التي يمكن الاستفادة منه حيث يمكن ان يسهم في

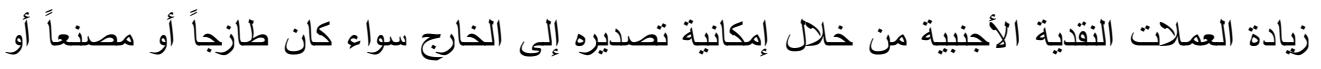

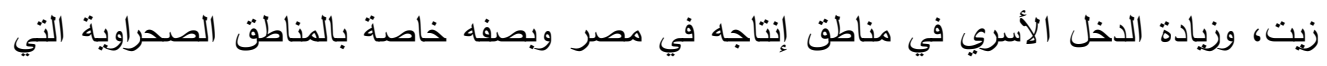

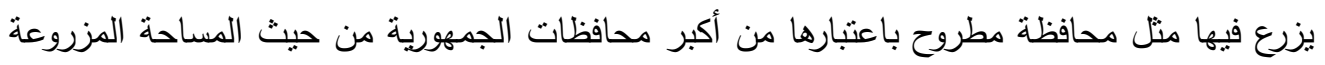

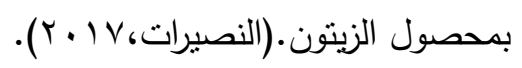
وقد تم اختيار مركز مطروح بالمحافظة لأنها من أكبر المساحات المزروعة بمحصول الزينون.

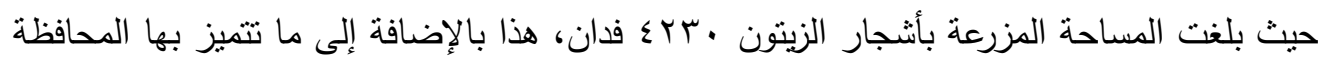
من تتوع أنماط الاستغلال الزراعي بها ويتميز مركز مرسي مطروح بزراعة المحاصيل الحقلية الهامة.

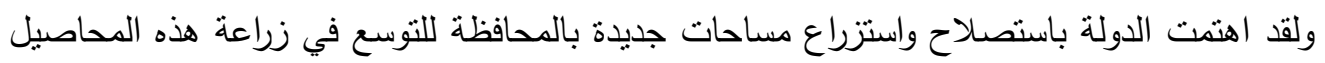

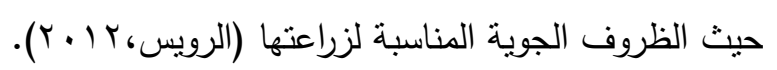

كما تسهم هذه المساحات في تحقيق التتمية الزراعية بالمحافظة، كما أن محصول الزيبتون من المحاصيل ذات الأهمية الغذائية الكبيرة حيث يسهم استهلاكها في زيادة مستوى الصحة العامة للإنسان حيث يحتوى الزيتون على مواد كربوهيدرات وبروتين ودهون وأحماض عضوية وألياف.

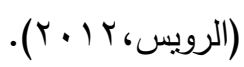

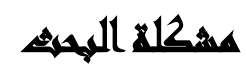

باتت قضية الموارد المائية، من أهم القضايا التي تُواجه المُجتمع المصري في الآونة الأخيرة،

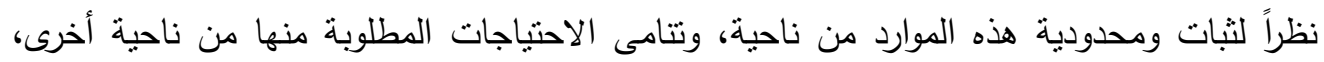

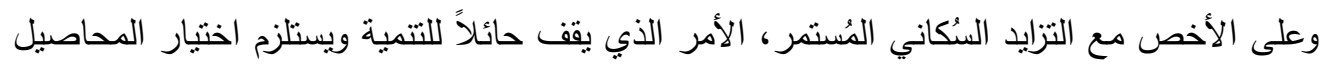
التي تجود بالمحافظة والتي يعظم وحدة العائد من المياه منها. وقد جاء الزيتون كمنتج هام يهنم به البدوي لما له من أهمية حيث قله احتئه احتياجاته المائية والكفاءة 
الاقتصادية لعناصر الإنتاج وتأثيرها على الإنتاج وعلى الناتج الكلي للزيتون في أراضي مطروح

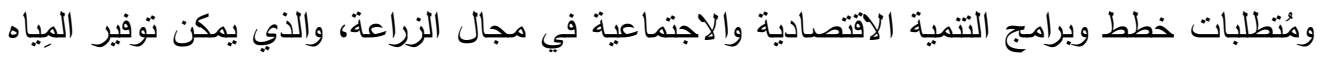
الضرورية له من الموارد المائية المحلية. وقد أدى الارتفاع الملحوظ في تكاليف الإنتاج لمحصول

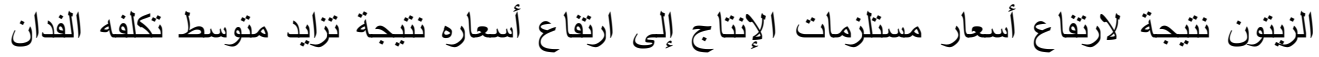
ومتوسط سعر الوحدة من الناتج النهائي الكلي وكذلك انخفاض العائي العائد من الوحدة الإروائية للتركيب

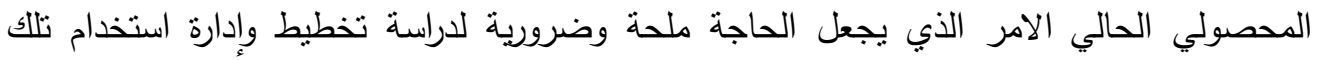
الموارد بطريقة تعظم العائد من تلك الموارد وتوجه منظومة التتمية الزراعية بمحافظة

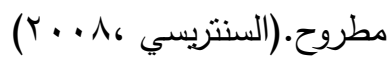

\section{همبنم المهيه}

يهدف البحث إلى تقدير دوال الإنتاج للتعرف على اهم عناصر الإنتاج الحددة لإنتاج الزيتون وكذا تقدير مرونة الإنتاج لتالك العناصر وحساب المرونة الاجمالية المحددة لطبيعة المرحلة الإنتاجية، وكذلك تقدير دوال التكاليف لقياس الحجم الأمثل لمزارع الزيتون في وتحديد عوائد السعة ووفورات

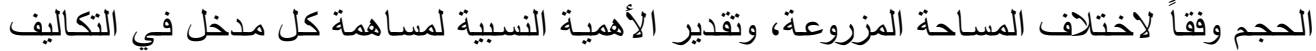
الكلية، وكذا نقدير الكفاءة الاقتصادية لعناصر الإنتاج، وبما يمكن من الاستفادة القصوى من عناصر

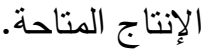
مصادر البيانات والطريقة البحثية: يعتد البحث في تحقيق اهدافه على البيانات الأولية النى تم

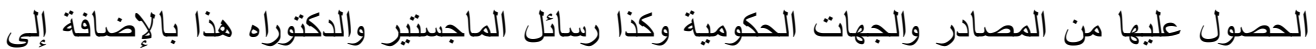
اعداد استمارة استبيان لمزارعي الزيتون في محافظة مطروح، وتضمنت عملية تحليل البيانات استخدام بعض المعايير الإحصائية الوصفية والكمبة الهتمنلة في الهتوسط الحسابي والأهمية النسبية. بالإضافة التافية

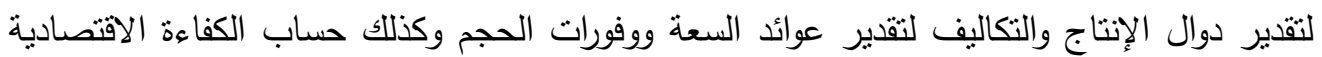
وتم اختيار عينه الدراسة من مزارعي الزينون بمركز مطروح كونه أهم مراكز الححافظة وفقاً للأهمية

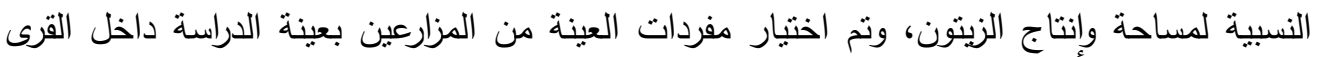

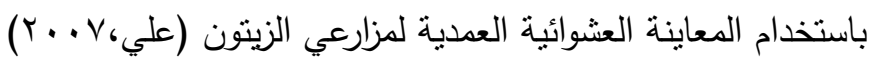

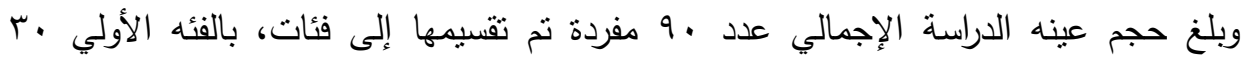

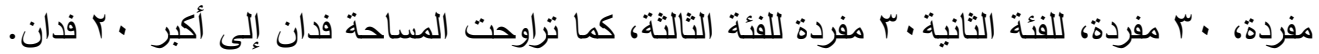


وتم تقسيم مزارع الدراسة إلى ثلاث فئات حيازية، للفئة الحيازية الأولي (من ا فدان حتي 7 فدان )،

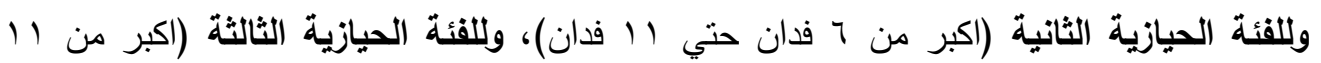

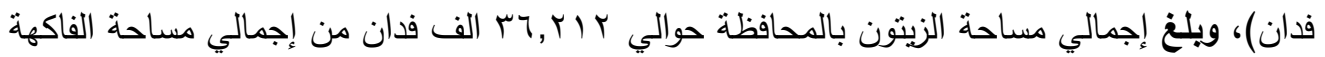

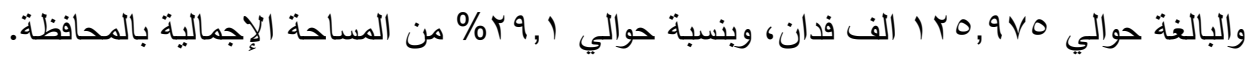

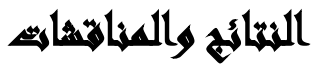

وقد أظهرت النتائج أن لتقدير معالم الدالة الإنتاجية لمحصول الزيتون من بيانات عينة البحث وفقاً للنموذج المقدر في صورة (كوب-دوجلاس) المحول إلى الصورة اللوغاريتمية المزدوجة لتبسيط تقدير مشتقات الدالة وسهولة تفسيرها، بإدخال جميع العناصر الإنتاجية المؤثرة على الناتج الكلي للفدان من محصول الزيتون حيث تبين من دالة الناتج الكلي (Q) أن أهم العناصر الإنتاجية ذات التأثير المعنوي

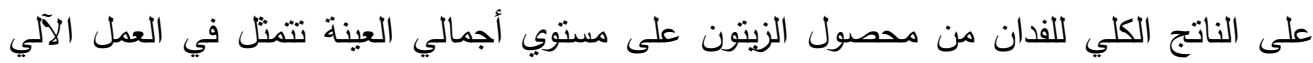
وكمية السماد البلاي، وعلى مستوي الفئة الأولي تتمنل في عدد ساعات العمل الآلي وعدد ساعات العمل البشري وكمية السماد البلاي وكمية المبيدات وكمية المياه، وعلى مستوي الفئة الحيازية الثنانية تتمنت في عدد ساعات العمل الآلي وعدد ساعات العمل البشري وكمية السماد البلاي، على مستوي الفئة الحيازية الثالثة تتمثل في العمل البشري وكمية السماد البلدي، وقدرت المرونة الإنتاجية الإجمالية

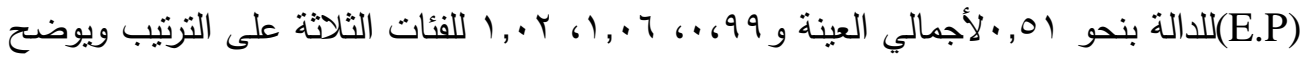
ذلك أن الإتتاج يتم في المرحلة الثانية للإنتاج حيث أن نسبة الزيادة في كمية الناتج الكلي للفدان أكبر

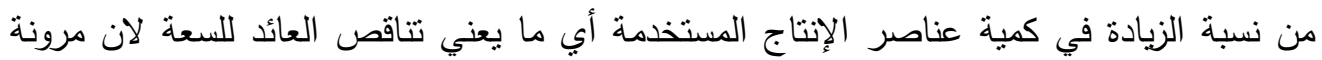
الإنتاج اقل من الواحد الصحيح. ويدلك ويوضح ذلك أن الإنتاج يتم في نهاية المرحلة الأولي للإنتاج حيث أن نسبة الزيادة في كمية الناتج الكلي للفدان أكبر من نسبة الزيادة في كمية عناصر الإنتاج المستخدمة أي ما يعني إلى أنها تقترب من تتاقص العائد للسعة. كما قدرت قيمة الناتج الحدي لئه لتلك العناصر الإنتاجية بحوالي TY,V (V.M.P) • • 109,V 
ويتبين أن حجم الإنتاج الأمتل الذي يخفض التكاليف لإنتاج الزيتون بإجمالي عينة الدراسة بلغ

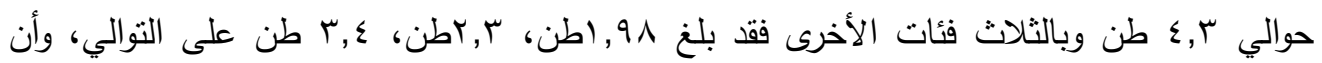
حجم الناتج الكلي الفعلي للمزرعة لإجمالي العينة قد بلغ نحو ب, ب طن أب اقل من حجم الإنتاج

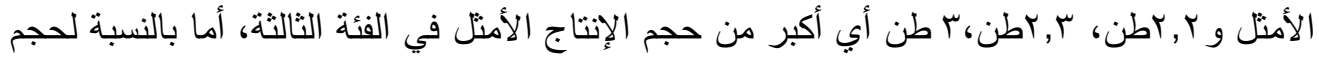
الإنتاج الاقتصادي الذي يعظم الربح فقد بلغ حوالي و,؛ طن في إجمالي العينة وبلغ في الفئات

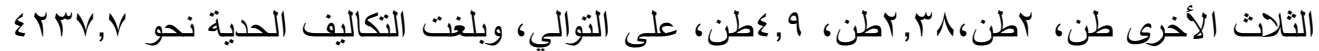
جنيه على مستوي العينة، وبلغت على مستوي الفئات نحو TY. Y.,V9

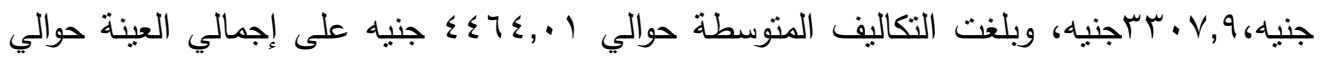

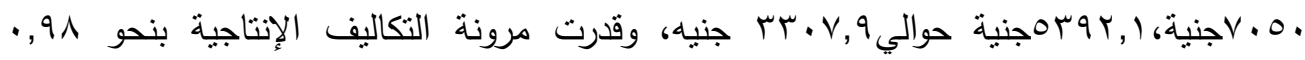

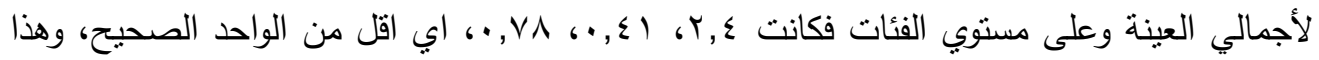
يدل على أن إنتاج الزيتون على مستوى إجمالي عينة الدراسة لا يحقق كفاءة اقتصادية نظراً لأن الإنتاج يتم في مرحلة تتاقص العائد للسعة وهي المرحلة غير اقتصادية للإنتاج، ولا يستطيع المنتج

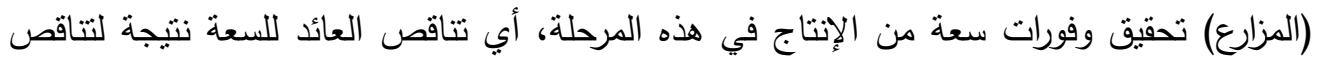

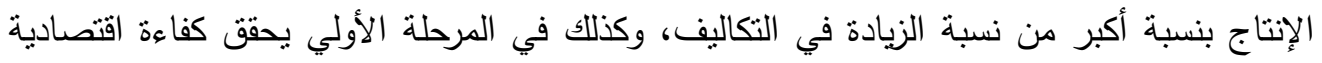

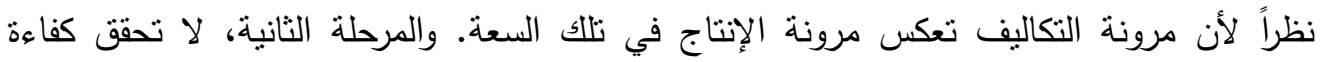
اقتصادية نظراً لأن الإنتاج يتم في مرحلة تتافص العائد للسعة من قانون تناقص الغلة وهي مرحلة

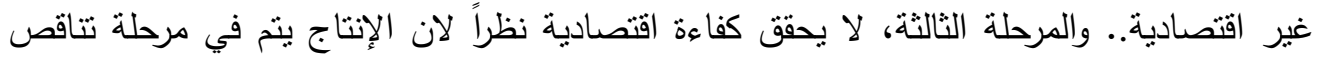
العائد للسعة وهي مرحلة غير اقتصادية.

\section{أولاً: تقدير دوال الإنتاج لمحصول الزيتون بعينة الدراسة:}

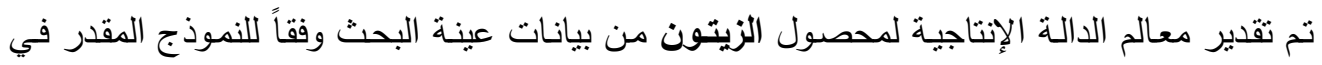
صورة (كوب - دوجلاس) المحول إلى الصورة اللوغاريتمية المزدوجة لتبسيط تقدير مشتقات الدالـة

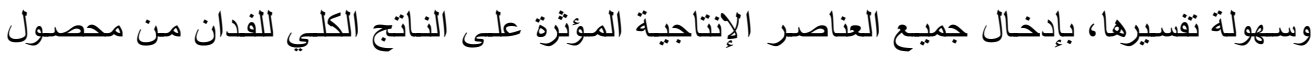

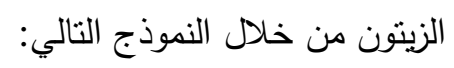
$\ln Q=\ln \alpha+\beta_{1} \ln X_{1}+\beta_{2} \ln X_{2}+\beta_{3} \ln X_{3}+\ldots . .+\beta_{5} \ln X_{6}$ 


$$
\begin{aligned}
& \text { = = Q }=\text { Q } \\
& \text { = = X, } \\
& \text { = = Xr } \\
& \text { = = Xr }
\end{aligned}
$$

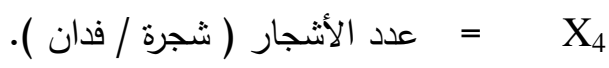

$$
\begin{aligned}
& \text { = }=X_{5} \\
& \text { = }=X_{6} \\
& \text { = B }
\end{aligned}
$$

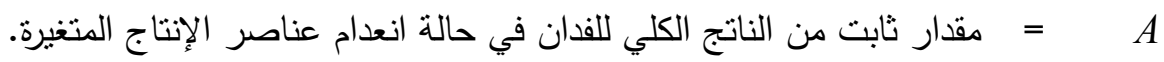

$$
\begin{aligned}
& \text {. • } 2.3 \mathrm{Ln}
\end{aligned}
$$

ويتم تقدير دوال الإنتاج على مستوي عينة الدراسة، كذلك الفئات الحيازية الثلاث. (1)دالة إنتاج محصول الزيتون على مستوي إجمالي عينة الاراسة: نم تحديد عناصر الإنتاج ذات التأثير الإيجابي المعنوي على إنتاج محصول الزيتون في المدى الطويل لإجمالي عينة من خلال النموذج المقدر لدالة الناتج الكلي للفدان من محصول الزينون باستخدام الانحدار المتعدد المرحلي (التدريجي) في الصورة اللوغاريتمية المزدوجة، والموضحة بالمعادلة التالية: $\ln \mathbf{Q}=3.9+0.07 \ln \mathbf{X}_{1}+0.44 \ln \mathbf{X}_{\mathbf{3}}$

(3.5) $\quad(2.8) \quad(5.8)^{* * *}$

$\overline{\mathrm{R}}^{2}=0.96 \mathrm{~F}=2317$

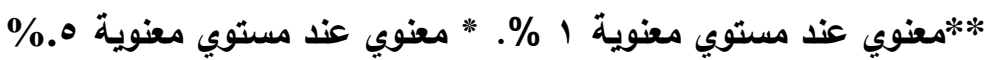
المصدر: جمعت وحسبت من نتائج الاستبيان الخاص بالدراسة.

حيث تبين دالة الناتج الكلي (Q) أن أهم العناصر الإنتاجية ذات التأثير المعنوي على النانج الكني للفدان من محصول الزيتون تتمثل في العمل الآلي وكمية السماد البلدي، وبتقدير مرونات الإنتاج

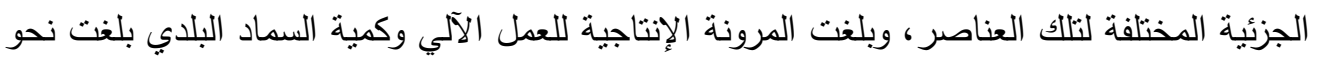

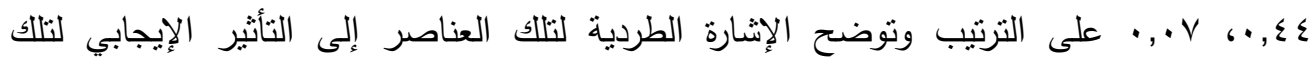

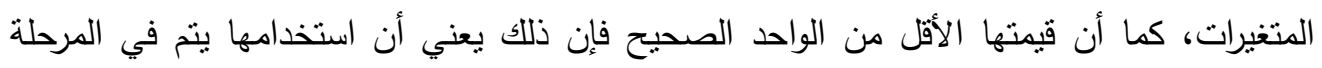
الإتتاجية الثانية (مرحلة الإنتاج الاقتصادي)، مما يشير إلى أن زيادة الكمية المستخدمة من العناصر 
J. Environ. Sci.

Institute of Environmental Studies and Research - Ain Shams University

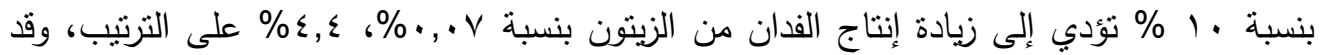

$$
\text { ثنتت المعنوية هذه النتائج إحصائياً. }
$$

وقدرت المرونة الإنتاجية الإجمالية (E.P.) للالة بنحو 0 (0. • وهي أقل من الواحد الصحيح وهذا

يعني أن زيادة هذه العناصر الإنتاجية بالدالة المقدرة بنسبة ـ 1\% يؤدي إلى زيادة الناتج الكلي للفدان

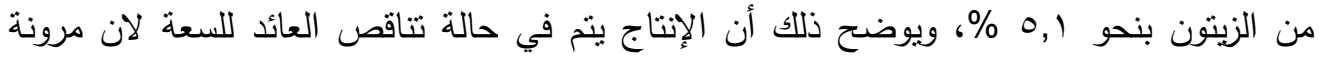
الإنتاج اقل من الواحد الصحيح. بأهون

وقد بلغ معامل التحديد المعدل ( $\left.{ }^{2}\right)$ حوالي 97 , •، مما يشير إلى أن تلك المتغيرات المستقلة المفسرة بالدالة المقدرة مسئولة عن حوالي 97 \% من التغيرات الكلية الحادثة في الناتج الكلي للفدان من محصول الزيتون، وتتثير قيمة(F) إلى المعنوية الإحصائية للالة المقدرة عند مستوى معنوية

كما نبين من جدول (1) أن الناتج المتوسط (A.P.) من محصول الزيتون بالنسبة لكلاً من

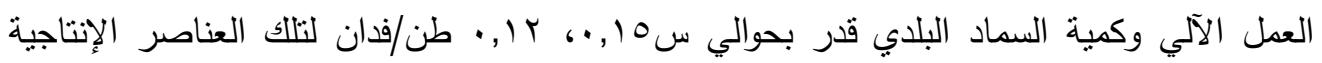
على الترتيب. جدول (1): مؤشرات الكفاءة الاقتصادية لاستخدام عناصر الإنتاج المستخدمة في دالة إنتاج الزيتون

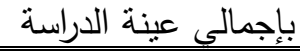

\begin{tabular}{|c|c|c|}
\hline \multicolumn{2}{|c|}{ عناصر الإتتاج (المدخلات) في دالةُ الناتج الكلي } & \multirow{3}{*}{ 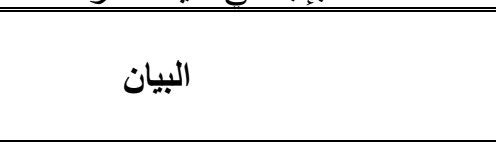 } \\
\hline كمية السماد البلادي & العمل الألي & \\
\hline $\mathbf{X}_{\mathbf{3}}$ & $\mathbf{X}_{1}$ & \\
\hline 25.3 & 15.8 & X متوسط كمية عنصر الإنتاج \\
\hline 0.44 & 0.07 & المرونة الإنتاجية لعنصر الإنتاج(E.X.) \\
\hline 0.12 & 0.15 & الناتج المتوسط( (A.P.) طن/ فدان) \\
\hline 0.05 & 0.01 & الناتج الحدي( (M.P.) طن/ فدان) \\
\hline 327.4 & 66.7 & فيمة الناتج الحدي( (V.M.P.) جنيه) \\
\hline 50 & 140 & سعر وحدة عنصر الإنتاج(PX) (جنيه) \\
\hline 6.5 & 0.5 & الكفاءة الاقتصادية(E.E.) \\
\hline
\end{tabular}

"سعر وحدة الناتج الرئيسي (سعر طن الزيتون) = . . . جنيه، متوسط الناتج الكلي لإجمالي العينةه,rطن/

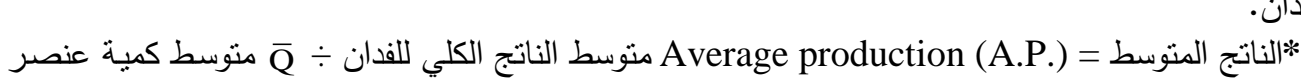
الإنتاج للفدان. 
Marginal production (M.P.) = المرونة الإنتاجية لعنصر الإنتاج × (E.X.) الناتج الحستج (A.P.). المتوسط

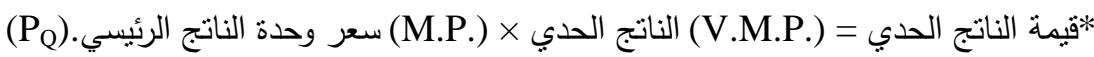

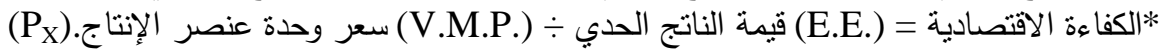
المصدر : جمعت وحسبت من نتائج الاستبيان الخاص بالألاسراسة.

وبتقدير تقدير الناتج الحدي والناتج المتوسط بالنسبة لكل عنصر إنتاجي في دالة الناتج الكلي المقدرة لمحصول الزيتون لإجمالي عينة الدراسة، حيث تبين من جدول ( (1) أن الناتج الددي (M.P)

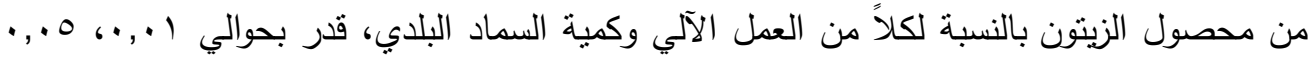

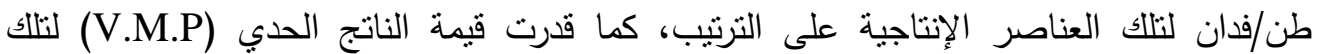

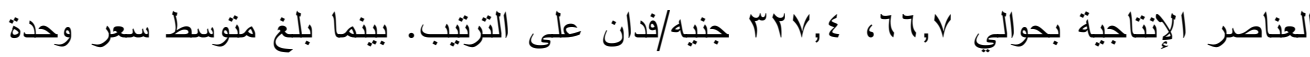
العمل الآلي بنحو •ـا جنيه / ساعة وكمية السماد البلدي نحو ـ جنية / للفدان. وبتقدير الكفاءة الاقتصادية لاستخدام العناصر الإنتاجية بدالة الناتج الكلي المقدرة، نبين من ونه

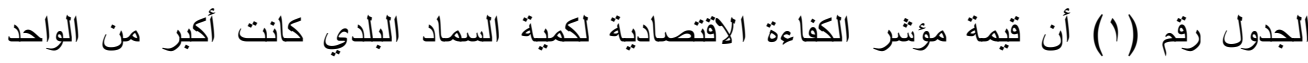

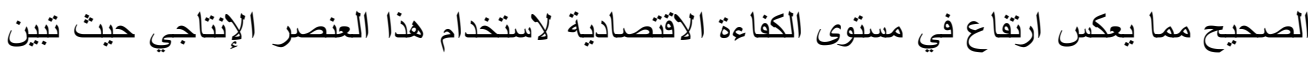
ارتفاع قيمة الناتج الحدي للعنصر الإنتاجي عن سعر وحدة العناصر الإنتاجية، اما عن كمية العمل

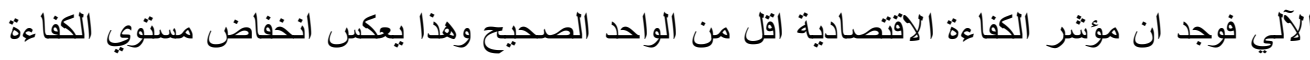
في تلك العنصر . (2) دالـة إنتاج الزيتون للفئة الحيازيـة الأولـي (من ا فدان حتي 1 فدان): يتم تحديد عناصر الإنتاج ذات التأثير الإيجابي المعنوي على إنتاج محصول الزينون في المدى القصير للفئة الحيازية

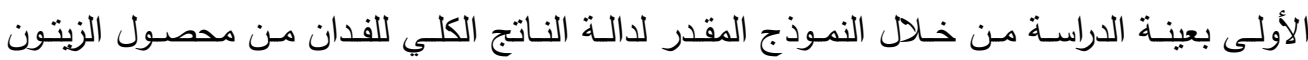

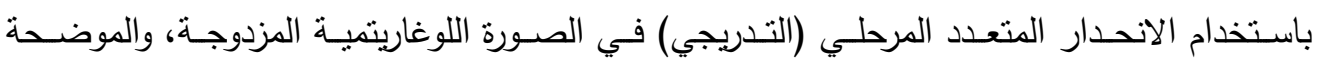

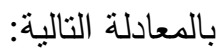

$$
\operatorname{Ln} \mathbf{Q}=2.66+0.42 \operatorname{Ln} \mathbf{X}_{\mathbf{1}}+0.46 \mathbf{L n} \mathbf{X}_{\mathbf{3}}+0.24 \operatorname{Ln} \mathbf{X}_{\mathbf{6}}
$$

$$
\begin{aligned}
& (23.4)^{* *}(4.9)^{* *} \quad(4.7)^{* *} \quad(2.4)^{*} \\
& \overline{\mathrm{R}}^{2}=\mathbf{0 . 9 8} \mathrm{F}=\mathbf{5 9 2}
\end{aligned}
$$

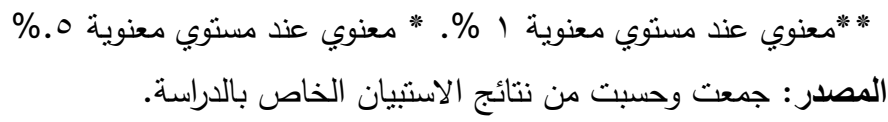


J. Environ. Sci.

Institute of Environmental Studies and Research - Ain Shams University

حيث تبين من دالة الناتج الكلي (Q) أن أهم العناصر الإنتاجية ذات التأثير المعنوي على الناتج

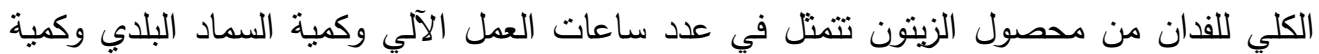

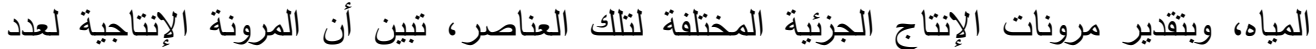
ساعات العمل الآلّي وعدد ساعات العمل البشري وكمية السماد البلدي وكمية المبيدات وكمية المياه

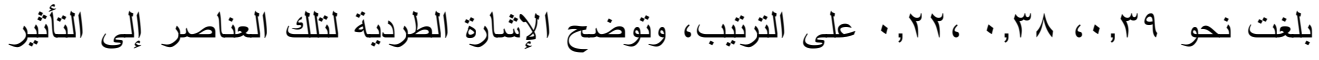

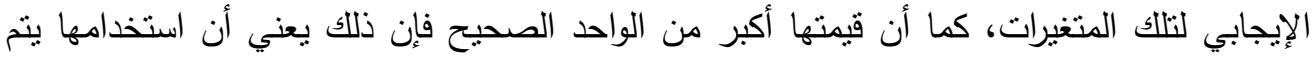

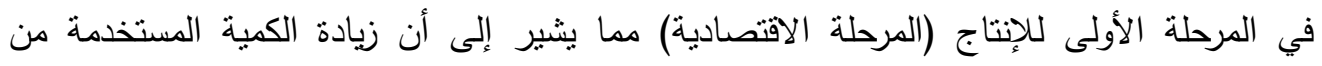

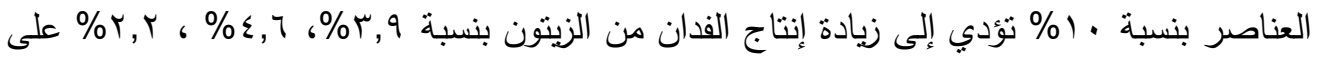

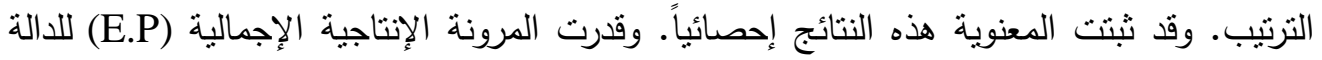

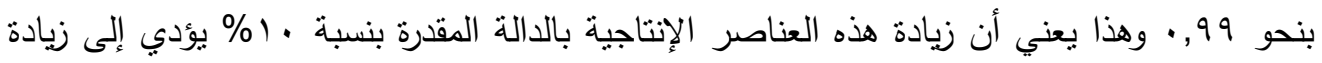

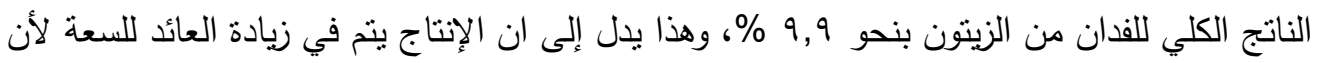
المرونة أكبر من الواحد الصحيح.

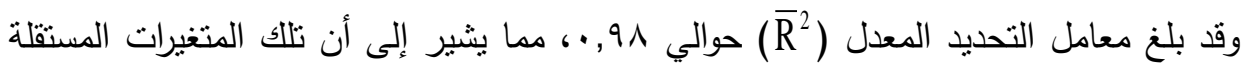

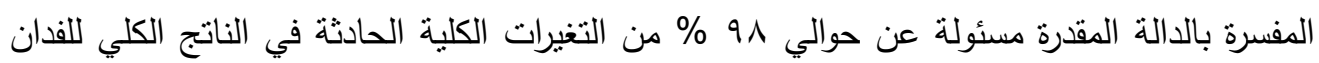

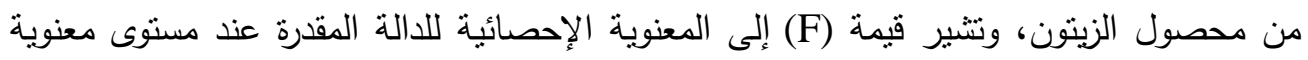
$.0 .01)$

كما تبين من جدول (ץ) أن الناتج الهنوسط (A.P) من محصول الزيتون بالنسبة لكلاً من عدد

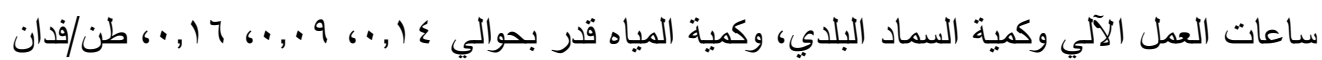
لتنلك العناصر الإنتاجية على التزتيب. 
جدول (r): مؤشرات الكفاءة الاقتصادية لاستخدام عناصر الإنتاج المستخدمة في دالة إنتاج الزيتون بالفئة الحيازية الأولى بعينة الدراسة.

\begin{tabular}{|c|c|c|c|}
\hline \multicolumn{3}{|c|}{ عناصر الإنتاج (المدخلات) في دالة الناتج الكلي } & \multirow{3}{*}{ 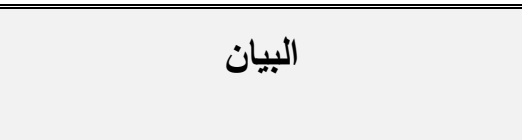 } \\
\hline كمية المياه & السماد البلدي & العمل الالىى & \\
\hline $\mathbf{X}_{6}$ & $\mathbf{X}_{3}$ & $\mathrm{X}_{1}$ & \\
\hline 14.1 & 25.2 & 15.7 & منوسط كمية عنصر الإنتاج \\
\hline 0.24 & 0.46 & 0.42 & المرونة الإنتاجية لعنصر الإنتاج(E.X) \\
\hline 0.16 & 0.09 & 0.14 & الناتج المتوسط( (A.P.) طن/ فدان) \\
\hline 0.037 & 0.040 & 0.059 & الناتج الحدي( (M.P.) طن/ فدان) \\
\hline 262.1 & 281.1 & 412.0 & قيمة الناتج الحدى( (V.M.P.) جنبه) \\
\hline 180 & 50 & 140 & سعر وحدة عنصر الإنتاج(P) (جنيه) \\
\hline 1.5 & 5.6 & 2.9 & الكفاءة الاقتصادية(E.E)( \\
\hline
\end{tabular}

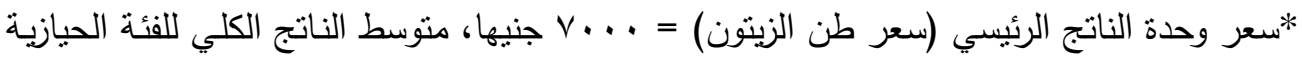

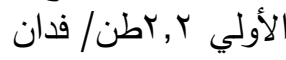

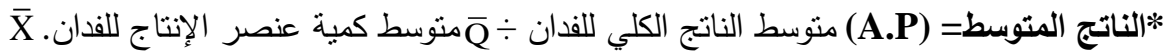

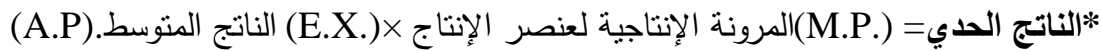

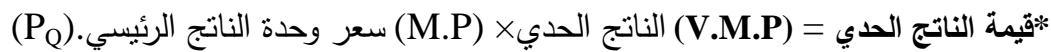

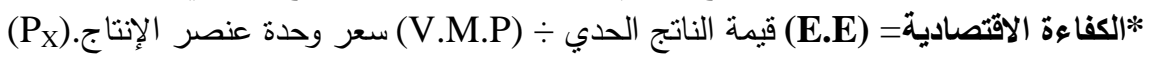

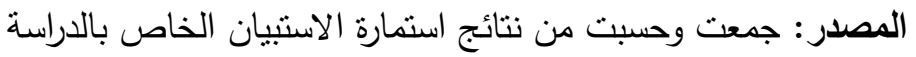

وبتقدير الناتج الحدي والناتج المتوسط بالنسبة لكل عنصر إنتاجي في دالة الناتج الكلي المقدرة

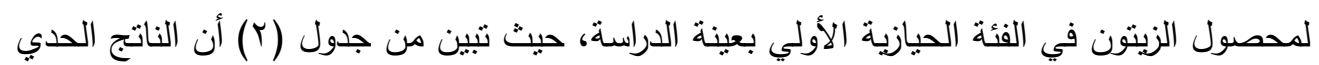

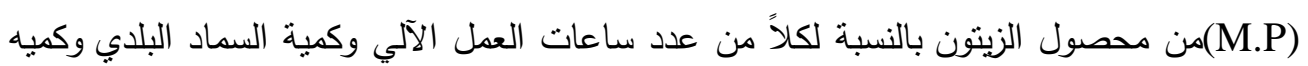

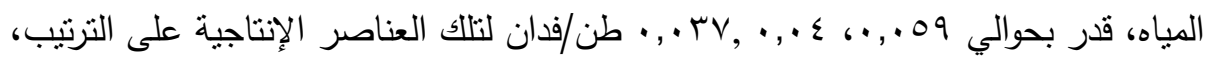

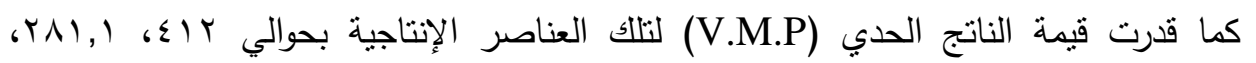
I., ومتوسط سعر وحدة كمية السماد البلدي نحو ـ0 جنيه/منز ب بينما بلغ منوسط سعر كمية وحدة المياه

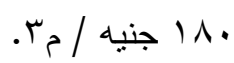
وبتقدير الكفاءة الاقتصادية لاستخدام العناصر الإنتاجية بدالة الناتج الكلي المقدرة، حيث تبين من

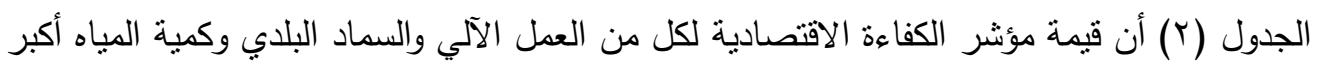
من الواحد الصحيح مما يشير إلى ارتفاع مستوى الكفاءة الاقتصادية لاستخدام هذه العناصر المذكورة ولنية 
J. Environ. Sci.

Institute of Environmental Studies and Research - Ain Shams University

حيث تبين زيادة قيمة الناتج الددي للعنصر الإنتاجي عن سعر وحدة العنصر الإنتاجي، وينصح باستخدام كميات إضافية من هذه العناصر .

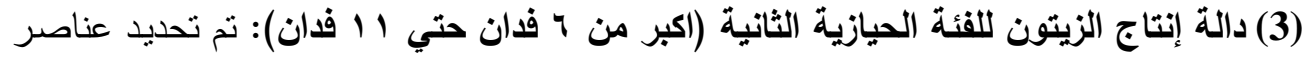

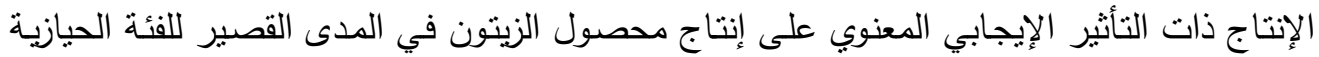

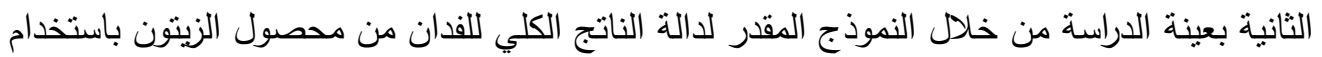

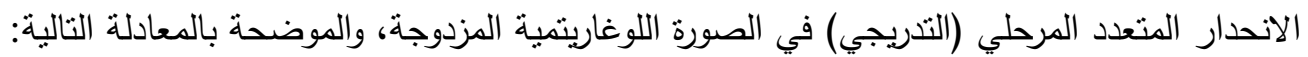
Ln $Q=3.7+0.27 \operatorname{Ln} X_{1}+0.54 \operatorname{Ln} X_{2}+0.25 \operatorname{Ln} X_{3}$

$$
\begin{aligned}
& (6.1)^{* *}(1.9)^{* *} \quad(3.6)^{* *} \quad(2.7)^{*} \\
& \overline{\mathrm{R}}^{2}=0.71 \mathrm{~F}=\mathbf{4 4 . 2}
\end{aligned}
$$

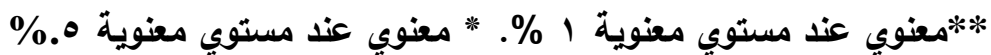

$$
\begin{aligned}
& \text { المصدر: جمعت وحسبت من نتائج الاستيان الخاص بالدري عنداسة }
\end{aligned}
$$

حيث تبين من دالة الناتج الكلي (Q) أن أهم العناصر الإنتاجية ذات التأثير المعنوي على الناتج

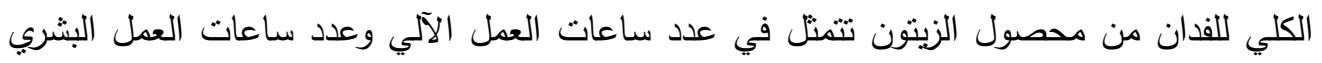

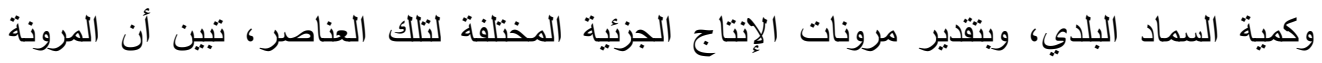

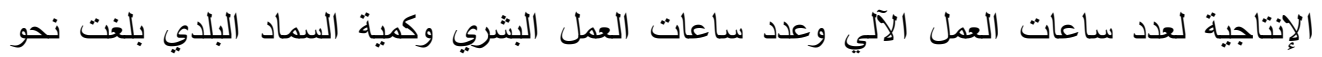
rV

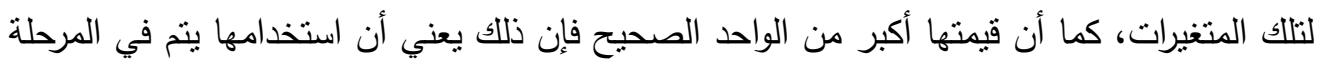
الإنتاجية الأولي ( المرحلة غير اقتصادية).

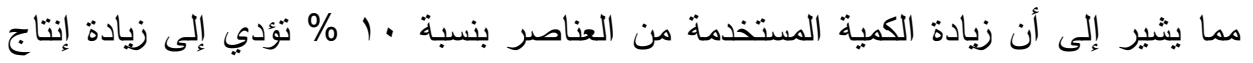

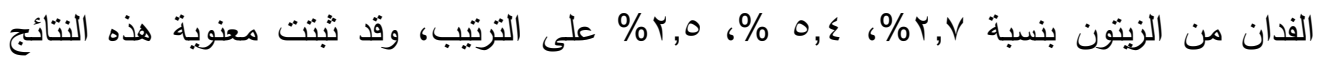
إحصائياً.

وقدرت المرونة الإنتاجية الإجمالية (E.P.) للادالة بنحو 7 ., وهي أكبر من الواحد الصحيح

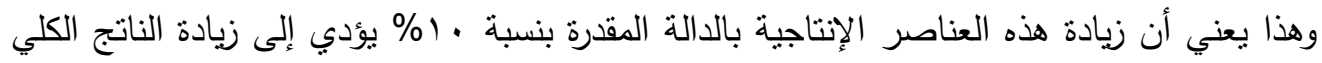

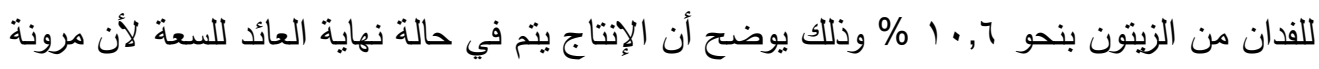

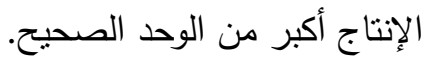


وقد بلغ معامل التحديد المعدل (

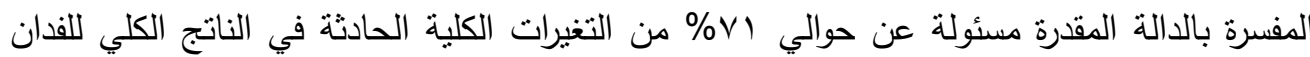

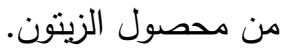
كما تبين من جدول (؟) أن الناتج المتوسط (A.P.) من محصول الزينون بالنسبة لكلاً من عدد

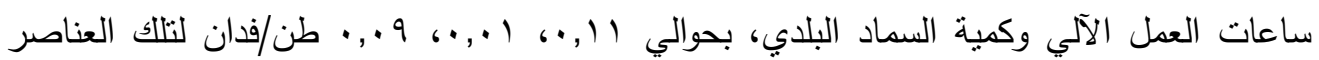
الإنتاجية على الترتيب. جدول (ץ): مؤشرات الكفاءة الاقتصادية لاستخدام عناصر الإنتاج المستخدمة في دالة إنتاج الزيتون بالفئة الحيازية الثانية بعينة الدراسة

\begin{tabular}{|c|c|c|c|}
\hline \multicolumn{3}{|c|}{ عناصر الإنتاج (المدخلات) في دالة الناتج الكلى } & \multirow{3}{*}{ 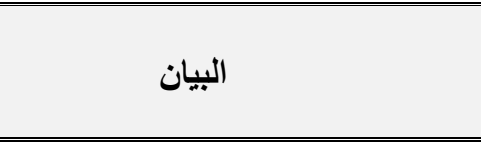 } \\
\hline السماد البلدي & العمل البشري & العمل الآلى & \\
\hline $\mathbf{X}_{\mathbf{3}}$ & $\mathbf{X}_{2}$ & $\mathrm{X}_{1}$ & \\
\hline 25.2 & 183.4 & 20.1 & X منوسط كمية عنصر الإنتاج \\
\hline 0.25 & 0.54 & 0.27 & المرونة الإنتاجية لعنصر الإنتاج(E.X) \\
\hline 0.09 & 0.01 & 0.11 & الناتج المتوسط( (A.P.) طن/ فدان) \\
\hline 0.02 & 0.01 & 0.03 & الناتج الحدي( (M.P.) طن/ فدان) \\
\hline 159.7 & 47.4 & 216.3 & قيمة الناتج الحدي( (V.M.P.) جنيه) \\
\hline 50 & 20 & 140 & سعر وحدة عنصر الإنتاج(PX) (جنيه) \\
\hline 3.2 & 2.3 & 1.5 & الكفاءة الاقتصادية(E.E.) \\
\hline
\end{tabular}

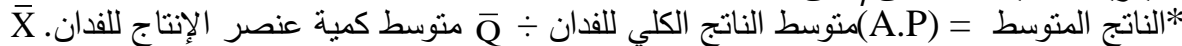

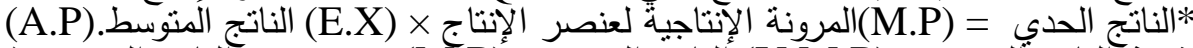

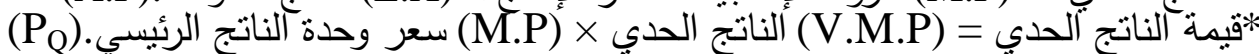

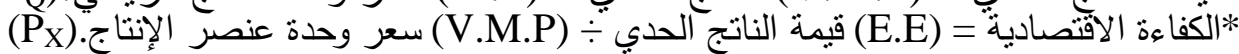
المصدر: جمعت وحسبت من نتائج الاستيان الخاص بالخ بالدراسة. وبتقدير الناتج الحدي والناتج المتوسط بالنسبة لكل عنصر النتان إنتاجي في دالة الناتج الكلي المقدرة لمحصول الزيتون في الفئة الحيازية الثانية بعينة الدراسة، حيث تبين من جدول (r) أن الناتج الحدي

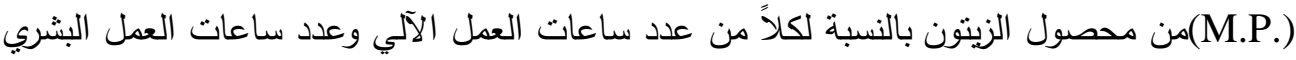

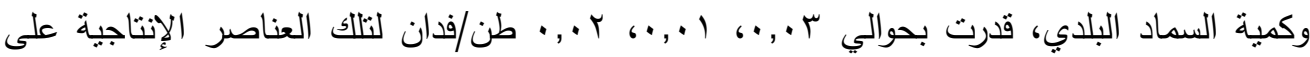

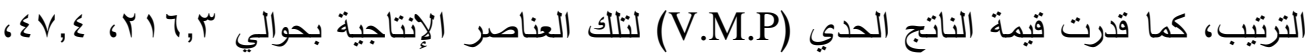


109,V وحدة العمل البشري نحو •r جنيه/ساعة أما عن وحدة السماد البلدي فقد بلغت نحو ـ0 جنيه/متر r. وبنقدير الكفاءة الاقتصادية لاستخدام العناصر الإنتاجية بدالة الناتج الكلي المقدرة، حيث تبين من الجدول (r) أن قيمة مؤشر الكفاءة الاقتصادية للعمل الآلي والعمل البشري وكمية السماد البلدي أكبر من الواحد الصحيح مما يشير إلى ارتفاع مستوى الكفاءة الاقتصادية لاستخدام هذه العناصر المذكور لهنير

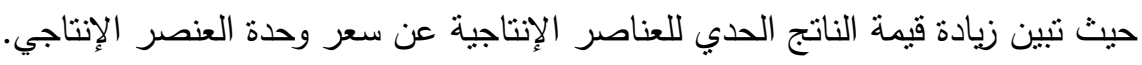

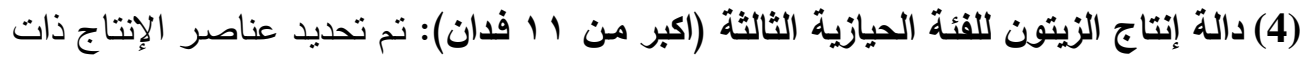
التأثثر الإيجابي المعنوي على إنتاج محصول الزيتون في المدى القصير للفئة الحيازية الثالثة بعينة

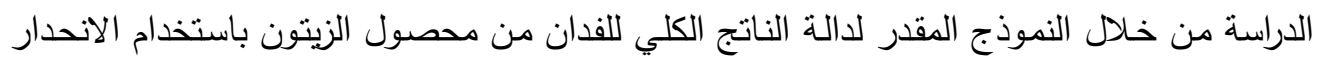
المتعدد المرحلي (التدريجي) في الصورة اللوغاريتمية المزدوجة، والموضحة بالمعادلة التالية: $\ln \mathbf{Q}=\mathbf{3 . 4 +} 0.59 \ln \mathbf{X}_{\mathbf{2}}+0.43 \ln \mathbf{X}_{\mathbf{3}}$

$(3.1) * *(3.7) * *(2.7) 8 *$

$\overline{\mathrm{R}}^{2}=\mathbf{0 . 4 9} \mathrm{F}=\mathbf{2 7 . 4}$

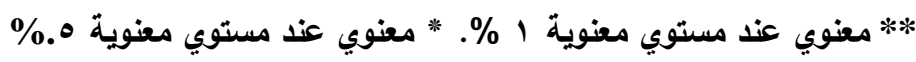

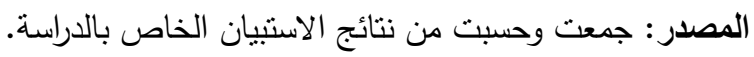

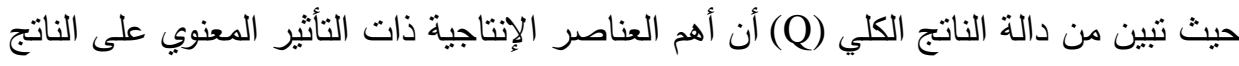
الكلي للفدان من محصول الزيتون تتمنل في العمل البشري وكمية السماد البلدي، وبتقدير مرونات الإنتاج الجزئية المختلفة لتلك العناصر ، تبين أن المرونة الإنتاجية للعمل البشري وكمية السماد البلدي

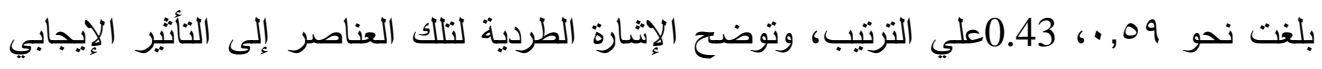

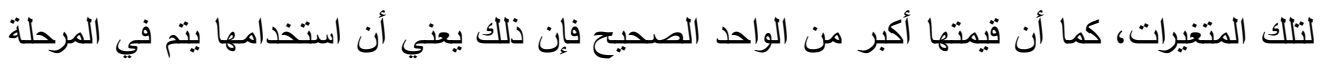
الإنتاجية الأولي (المرحلة غير اقتصادية).

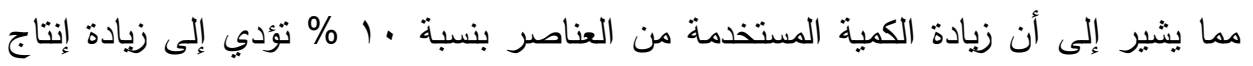
الفدان من الزيتون بنسبة 5.9\% ، 4.3\% على الترتيب، وقد ثبتت المعنوية هذه النتائج إحصائياً. وقدرت المرونة الإنتاجية الإجمالية (E.P.) للدالة بنحو 1.02 وهي أكبر من الواحد الصحيح وهذا يعني أن زيادة هذه العناصر الإنتاجية بالدالة المقدرة بنسبة ـ (1\% يؤدي إلى زيادة الناتج الكلي للفدان من الزيتون بنحو 10.2 ، ويوضح ذلك أن الإنتاج يقترب من نتاقص العائد للسعة، وقد بلغ معامل 
التحديد المعدل)

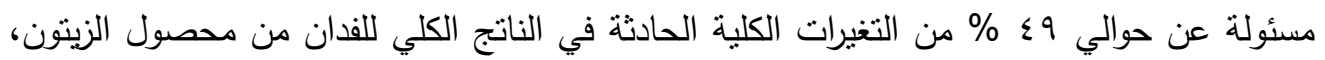
وتتير قيمة(F) إلى المعنوية الإحصائية للدالة المقدرة عند مستوى معنوية(0.01) .

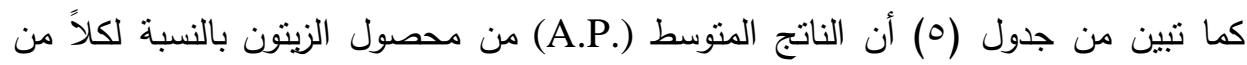

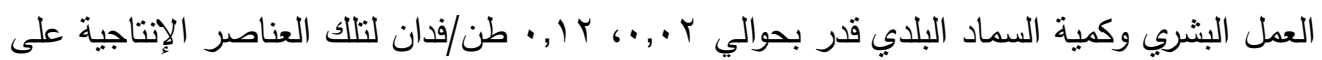
الترتيب. جلول (•): مؤشرات الكفاءة الاقتصادية لاستخدام عناصر الإنتاج المستخدمة في دالة إنتاج الزيتون بالفئة الحبازية الثالثة بعينة الدراسة

\begin{tabular}{|c|c|c|}
\hline \multicolumn{2}{|c|}{ عناصر الإنتاج (المدخلات) في دالة الناتج الكلي } & \multirow{3}{*}{ 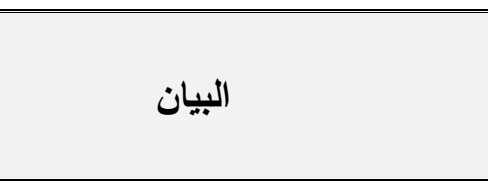 } \\
\hline كمية السماد البلاي/مجr & العمل البشري/ساعة & \\
\hline $\mathbf{X}_{\mathbf{3}}$ & $\mathbf{X}_{2}$ & \\
\hline 25.23 & 193 & X متوسط كمية عنصر الإنتاج X \\
\hline \multirow[t]{2}{*}{0.43} & 0.59 & المرونة الإنتاجية لعنصر الإنتاج(E.X) \\
\hline & 1.02 & المرونة الإنتاجية الإجمالية(E.P) \\
\hline 0.12 & 0.02 & الناتج المتوسط( (A.P.) طن/ فدان) \\
\hline 0.05 & 0.01 & الناتج الحدي( (M.P.) طن/ فدان) \\
\hline 357.9 & .2 & قيمة الناتج الحدي( (V.M.P.) جنيه) \\
\hline 50 & 20 & سعر وحدة عنصر الإنتاج(PX) (جنيه) \\
\hline 7.2 & 3.2 & الكفاءة الاقتصادية(E.E) \\
\hline
\end{tabular}

*سعر وحدة الناتج الرئيسي (سعر طن الزيتون 7000 = (جنيه، منوسط الناتج الكلي للفئة الحيازية الثالثةب

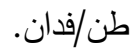

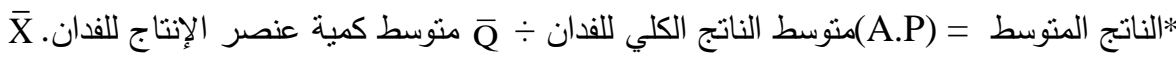

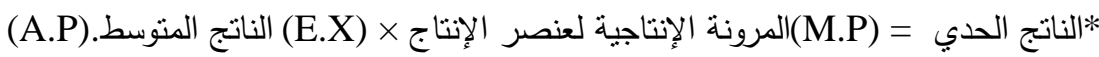

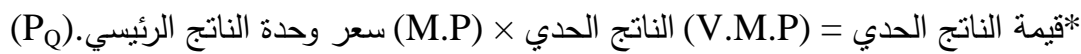

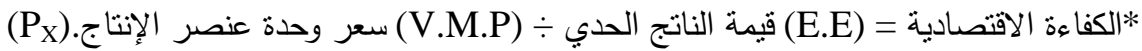
المصدر: جمعت وحسبت من نتائج الاستيان الخاص بالدراسة. وبتقدير الناتج الحدي والناتج المتوسط بالنسبة لكل عنصر الانئ إنتاجي في دالة الناتج الكلي المقدرة

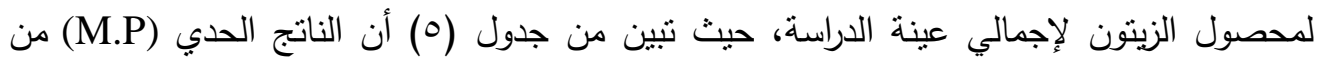


J. Environ. Sci.

Institute of Environmental Studies and Research - Ain Shams University

محصول الزيتون بالنسبة لكلاً من العمل البشري وكمية السماد البلدي، قدر بحوالي ا.,.، م. .,.

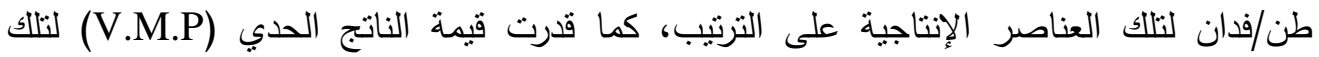

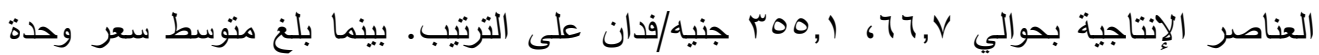

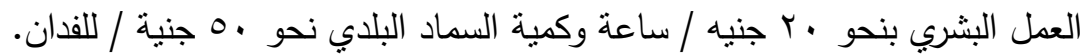

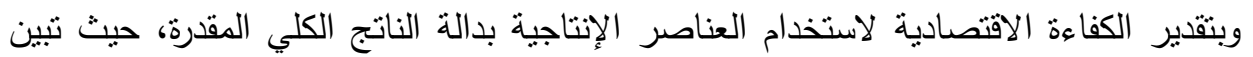
من الجدول (5) أن قيمة مؤشر الكفاءة الاقتصادية للعمل البشري وكمية السماد البلدي وجدت ألنها لأناءئ

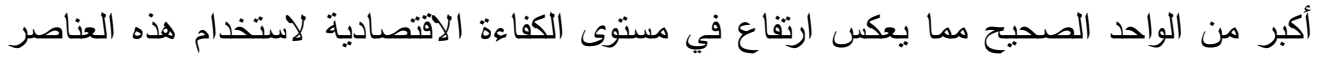
الإنتاجية حيث تبين ارتفاع قيمة الناتج الحدي للعنصر الإنتاجي عن سعر وحدة العناصر الإنتاجية. أولا: التقير الإحصائي لدال تكاليف الزيتون بعينة الداسةة: وتعبر دالة النكاليف الإنتاجية عن الإنية

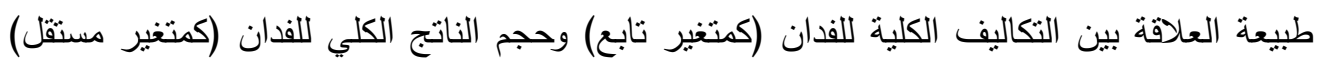
لمحصول زراعي معين، ويمكن التعبير عن دالة التكاليف الكلية (T.C) للمحصول موضوع الدراسة لإنة

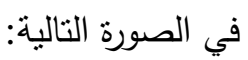

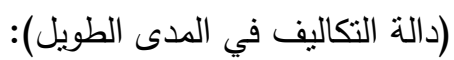

$$
\mathrm{T} . \mathrm{C}=\beta_{1} \mathrm{Q}-\beta_{2} \mathrm{Q}^{2}+\beta_{3} \mathrm{~S} \cdot \mathrm{Q}+\beta_{4} \mathrm{~S}^{2}
$$

T.C $=\alpha+\beta_{1} \mathrm{Q}-\beta_{2} \mathrm{Q}^{2}+\beta_{3} \mathrm{Q}^{3}$ (دالة التكاليف في المدى القصبر ) :

$$
\begin{aligned}
& \text { = T.C }
\end{aligned}
$$

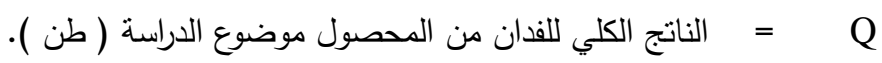

$$
\begin{aligned}
& \text { = S } \\
& \text { = } \quad \text { = المعلمات أو الثوابت الإحصائية للالة المقدرة. }
\end{aligned}
$$

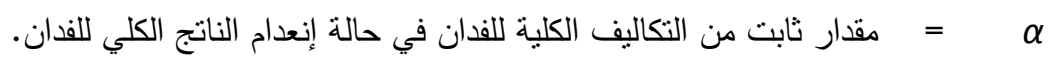

ويتم التقدير الإحصائي لدوال التكاليف لمحصول الزيتون في المدى القصير على مستوى كل فئة من ألفئات الحيازية الثلاث، وفي المدى الطويل لإجمالي العينة، للتعرف على الكفاءة الإنتاجية لكل فئة في عينة الدراسة الميدانية، وذلك من خلا تقدير دالة التكاليف الكلية (T.C) ثم إثتقاق دوال 
التكاليف الحدية (M.C) والتكاليف المتوسطة(A.C) ، ثم تقدير مرونة التكاليف الإنتاجية للتعرف على المرحلة الإنتاجية التي يتم فيه الإنتاج للمحصول موضوع الدراسة، وكذلك التعرف على حجم التح التحانه

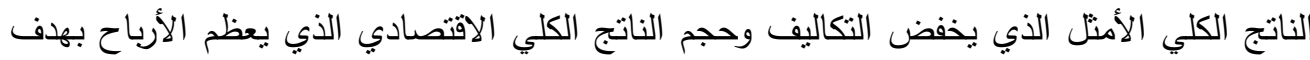

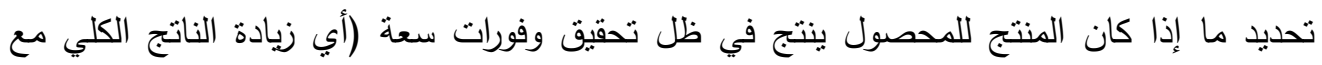
انخفاض التكاليف) أو في ظل تحقيق لا وفورات سعة (أي زيادة الإنتاج مع نزايد التكاليف)، وسيتم

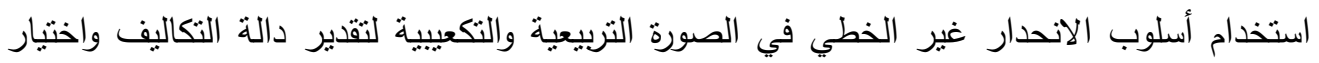
أفضلهما من حيث المنطق الاقتصادي والمعنوية الإحصائية. (1) دالة تكاليف إنتاج الزيتون على مستوى إجمالي العينة ( المدى الطويل ): بتقدير معالم دالة التكاليف الكلية (T.C) لإنتاج محصول الزيتون في المدي الطويل على مستوى إجمالي عينة الدراسة

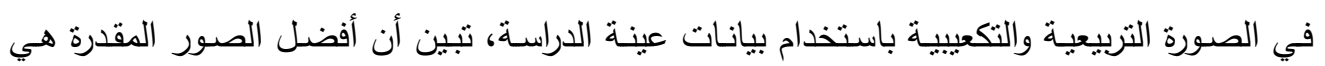

\section{T.C =7535.3 Q +573.7 $Q^{2}$ - 636.04Qs + 56.11S}

الدالة في الصورة التربيعية والموضحة بالمعادلة ( ) (1) $(16) * *(1.8)(-6.5)(4.6)$
$\mathbf{R}^{2}=0.98$
$\mathbf{F}=1180$

التكاليف الإتتاجية الكلية ( جنيه ) لإنتاج الزينون على مستوى إجمالي عينة الدراسة. الناتج الكلي الفعلي ( طن ) =

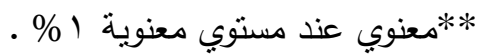
$s=14$

T.C = $10997.56-1369.26 \mathbf{Q}+573.7 \mathbf{Q}^{2} \leftarrow \mathbf{( 1 )}$ وتوضح دالة التكاليف الكلية (T.C) لإنتاج محصول الزيتون بإجمالي عينة الدراسة، أن الناتج الكلي

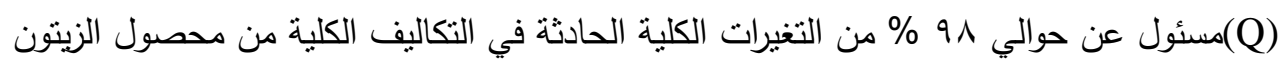

وبتقدير دالة التكاليف المتوسطة (A.C) في المدى الطويل وبالتالي الحصول على المعادلة (2): A.C = 10997.56/Q - 1369.26 +573.7 Q $\leftarrow$ ( $)$ وبتقدير دالة التكاليف الحدية (M.C) في المدى الطويل ويتم الحصول على دالة التكاليف الحدية M.C $=1369.26+1147.4 \mathbf{Q} \leftarrow \mathbf{( 3 )}$

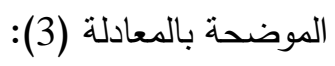


ويتبين أن حجم الإنتاج الأمنل الذي يخفض التكاليف لإنتاج الزيتون بإجمالي عينة الدراسة بلغ

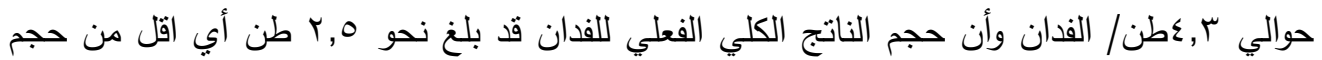

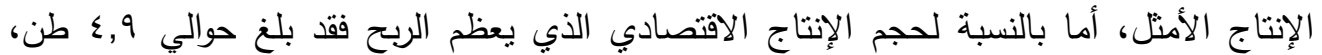
وقدرت مرونة التكاليف الإنتاجية بنحو 9 , • ·ما يدل على أن محصول الزينون على مستوى إجمالي الإلي عينة الدراسة لا يحقق كفاءة اقتصادية نظراً لأن تكاليف الإنتاج تتم في مرحلة نتاقص العائد للسعة

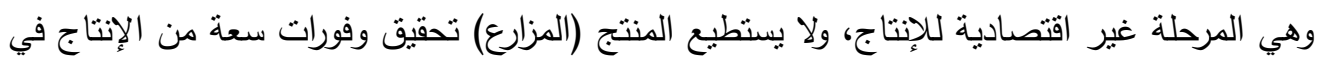
هذه المرحلة، أي تتاقص العائد للسعة نتيجة لنتاقص الإنتاج بنسبة أكبر من نسبة الزيادة في

جدول رقم (ه): مؤشرات نتائج دالة التكاليف لعينة الدراسة

\begin{tabular}{|c|c|c|c|c|}
\hline الفئة الحيازية & الفئة الحيازية & الفئة الحيازية & الفئة الإجمالية & \\
\hline 2 & 20.3 & 2.2.2 & 2.5 م 2.5 - ن & 1- منوسط الإنتاج \\
\hline 3.4 & ن2.3 & 1.98 & 4.3 4. & r- حجم الإتناج المدنى للتكاليف \\
\hline 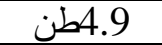 & - ل & 2 2 2 & 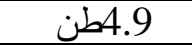 & r- حجم الإنتاج المعظم للرباح \\
\hline 0.79 & 0.41 & 0.84 & 0.98 & ع -مرونة النكاليف \\
\hline
\end{tabular}

( ) حجم الإنتاج المدني للتكاليف: يتحقق عند تساوي التكاليف الحدية (M.C) مع التكاليف المتوسطة

r) حجم الإنتاج المعظم للأرباح: يتحقق عند نساوي التكاليف الحدية (M.C) مع الإيراد الحدي وهو يساوي سعر وحدة الناتج النهائي.

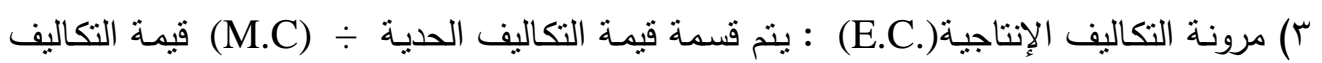

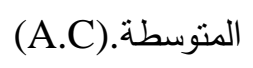

(2)دالة تكاليف إنتاج محصول الزيتون للفئة الأولـي بعينة الدراسـة: بتقدير معالم دالة التكاليف

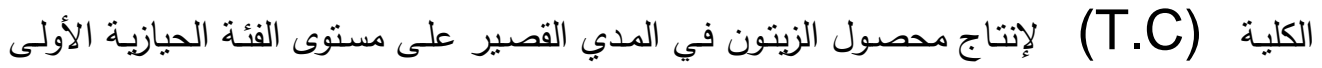

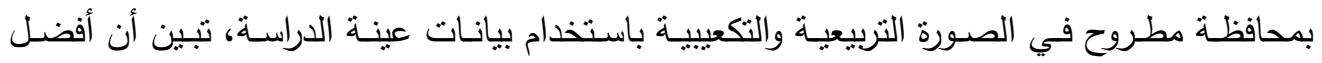
الصور المقدرة هي الدالة في الصورة التربعية، والموضحة بالمعادلة( ():

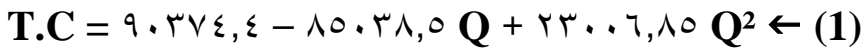

$\left(\{, 7)^{* *}(-4.4)^{* *}(4.0)^{* *}\right.$

$\mathbf{R}^{2}=0.84 \quad \mathbf{F}=82$ 
T.C

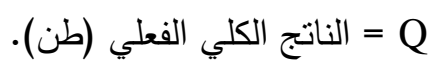

وتوضح دالة التكاليف الكلية (T.C) لإنتاج محصول الزينون بالفئة الحيازية الأولى، أن الناتج الكلي للفدان (Q) مسئول عن حوالي 84 \% من التغيرات الكلية الحادثة في التكاليف الكلية من محصول الزيتون، كما ثبتت معنوية الدالة ومعلماتها إحصائياً عند مستوى معنوية ال \%، وبتقدير دالة التكاليف المنوسطة (A.C) في المدى القصير ويتم الحصول على المعادلة (2): A.C $=90374.4 / \mathbf{Q}-85038.5+23006.85 \mathbf{Q} \leftarrow$ (2)

وبتقدير دالة التكاليف الحدية (M.C) في المدى القصير (1) يتم الحصول على دالة التكاليف الحدية M.C $=85038.5+46013.7 \mathbf{Q} \leftarrow \mathbf{( 3 )}$

الموضحة بالمعادلة (3): (3) ينتين أن حجم الإنتاج الأمنل الذي يخفض التكاليف لإنتاج الزيتون بالفئة الحيازية الأولى بلغ حوالي

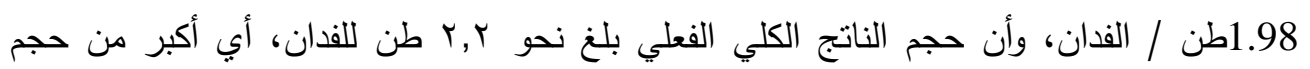

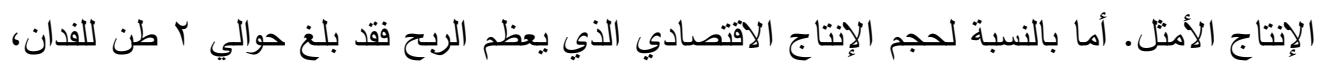

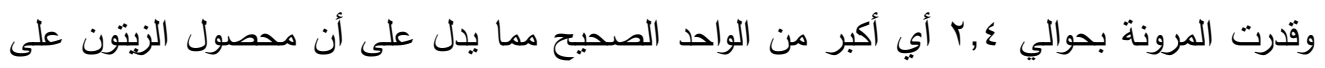

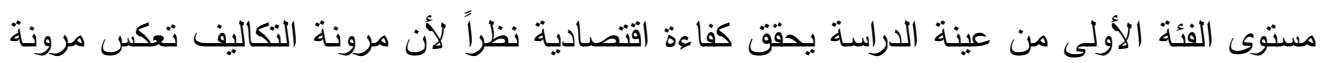

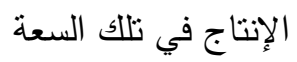
(3) دالة تكاليف إنتاج محصول الزيتون الفئة الثانيـة بعينـة الدراسـة: بتقدير معالم دالة التكاليف الكلية (T.C) لإنتاج محصول الزينون في المدي القصير على مستوى الفئة الحيازية الثانية بمحافظة

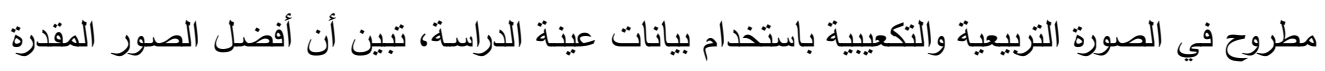
هي الدالة في الصورة التربيعية، والموضحة بالمعادلة( (1):

T.C = 159572.2- $130178 \mathbf{Q}+\mathbf{2 8 7 7 8 . 6 7} \mathbf{Q}^{2} \leftarrow$ (1)

$(2.8) * *(-2.6) *(2.6) *$

$\mathbf{R}^{2}=0.24 \quad \mathbf{F}=3.5$

حيث :

T.C = الناتج الكلي الفعلي (طن) Q 
وتوضح دالة التكاليف الكلية (T.C) لإنتاج محصول الزيتون بالفئة الحيازية الثانية، أن الناتج

الكلي للفدان (Q) مسئول عن حوالي 24\% من التغيرات الكلية الحادثة في التكاليف الكلية من بن التهنية

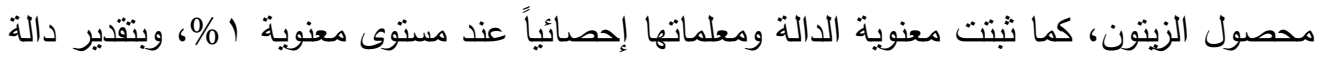
التكاليف المتوسطة (A.C) في المدى القصير ويتم الحصول على المعادلة (2): A.C $=$ 15957.2/ Q - $130178+$ 27778.67 $Q \leftarrow$ (2)

وبتقدير دالة التكاليف الحدية (M.C) في المدى القصير ويتم الحصول على دالة التكاليف

الحدية الموضحة بالمعادلة (3):

M.C = 130178+ $57557.34 \mathbf{Q} \leftarrow$ (3)

يتبين أن حجم الإنتاج الأمثل الذي يخفض التكاليف لإنتاج الزيتون بالفئة الحيازية الثانية بلغ

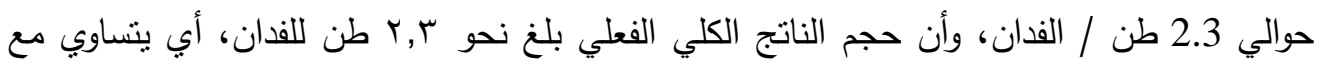

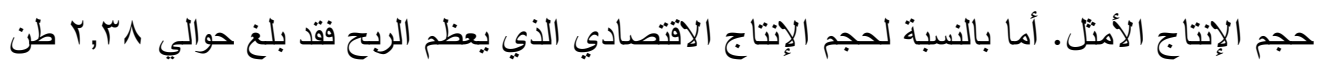

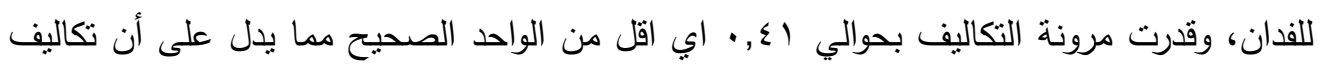

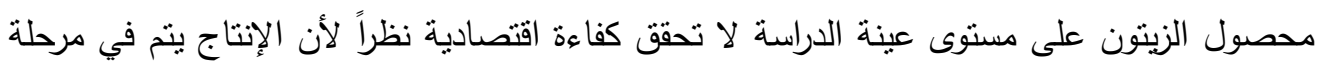
تتافص العائد للسعة من قانون تتاقص الغلة وهي مرحلة غير اقتصادية.

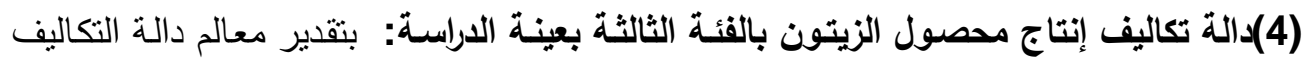
الكلية لإنتاج محصول الزيتون في المدي القصير على مستوى الفئة الحيازية الثالثة

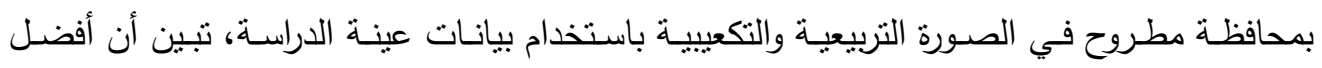

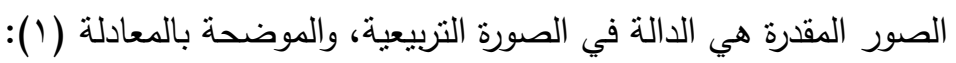
T.C =11264.73- $2363.25 \mathbf{Q}+945.2 \mathbf{Q}^{2} \leftarrow$ (1)

$(1.9)^{*}(-0.5)(1.4)$

$\mathbf{R}^{2}=0.79$ $\mathbf{F}=55$

T.C = الناتج الكلي الفعلي (طن) Q

وتوضح دالة التكاليف الكلية (T.C) لإنتاج محصول الزيتون بالفئة الحيازية الثالثة، أن الناتج

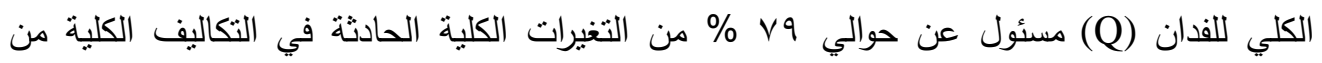


محصول الزيتون، كما ثبتت معنوية الدالة ومعلماتها إحصائياً عند مستوى معنوية ا \%، وبتقدير دالة التكاليف المتوسطة (A.C) في المدى القصير ، ويتم الحصول على المعادلة (2): A.C $=11264.73 / \mathbf{Q}-2363.25+945.2 \mathbf{Q} \leftarrow \mathbf{( 2 )}$

وبتقدير دالة التكاليف الحدية (M.C) في المدى القصير ويتم الحصول على دالة التكاليف الحدية الموضحة بالمعادلة (3):

M.C $=2363.25+1890.4 \mathbf{Q} \leftarrow \mathbf{( 3 )}$

ينتين أن حجم الإنتاج الأمثل الذي يخفض التكاليف لإنتاج الزيتون بالفئة الحيازية الثالثة بلغ

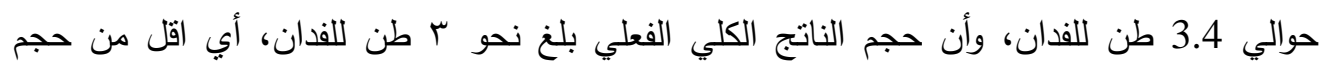

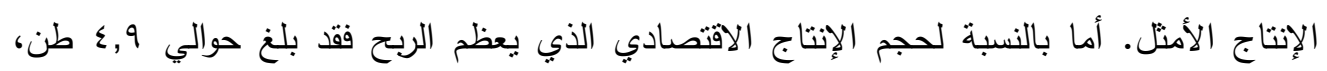

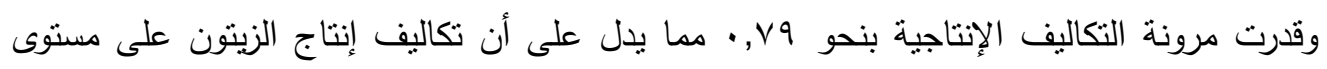

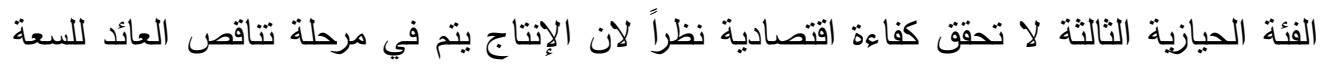
وهي مرحلة غير اقتصادية.

\section{اللتوكيايت}

توصي الدراسة بعدم إنتاج الزيتون في مرحلة تناقص العائد للسعة نظراً لأنه لا يحقق كفاءة

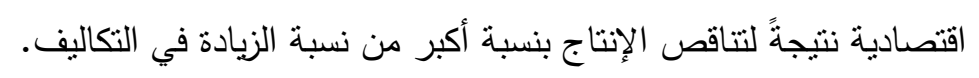

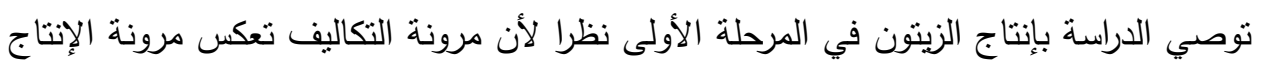
في تللك السعة مما يحقق كفاءة اقتصادية. توصي الدراسة بتطوير طرق حصاد الأمطار، والتعريف بتقنيات الري التكميلي الحديثة (الري

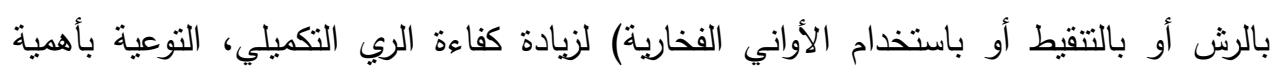

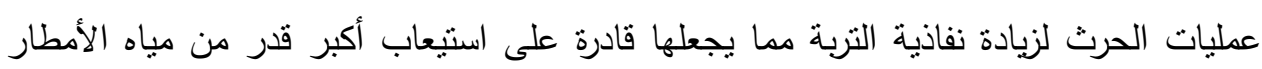
وتخزينها في طبقات تحت سطح التربة حتى تستقبد منها الأشجار خلال موسم النمو .

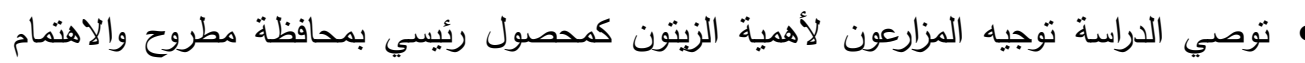

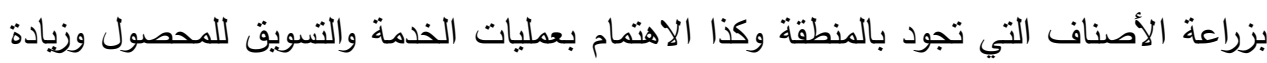

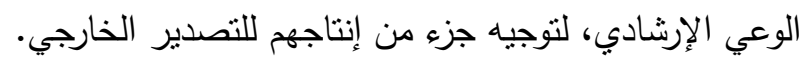


J. Environ. Sci.

Institute of Environmental Studies and Research - Ain Shams University

الاهتمـام بالعنصر البشري لأنـه من أهم العناصر الإتتاجية ذات التأثثر الإيجابي المعنوي على

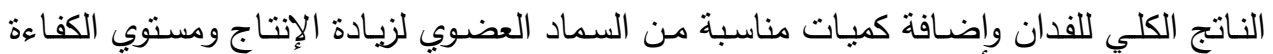

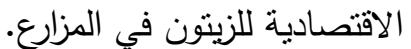

\section{sall}

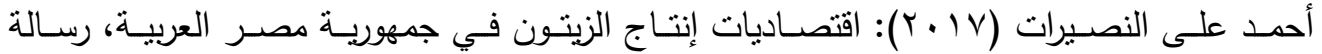

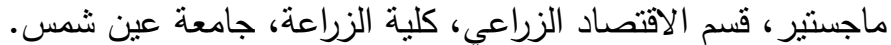

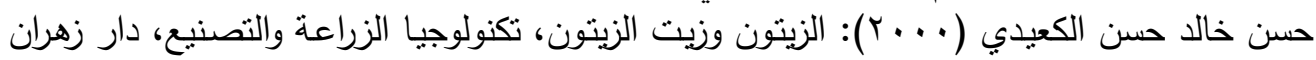

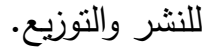

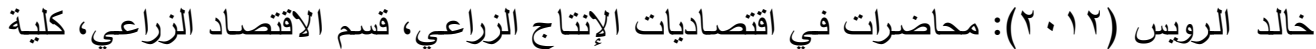

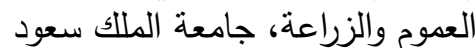

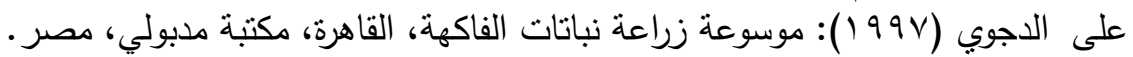

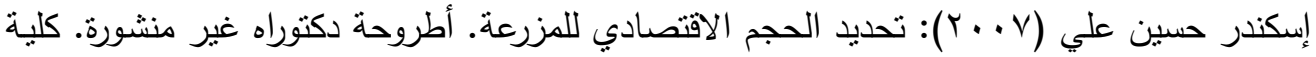

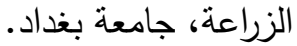

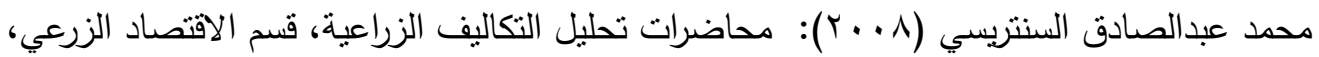
كلية الزراعة جامعة عين شمس. 


\title{
THE ECONOMIC ANALYSIS OF PRODUCTION AND COST FUNCTIONS OF OLIVE CROP AT MATROUH GOVERNORATE
}

Fathia M. Allam(1) - , Mohammed.S. Shehata, (2) Ahmed A. Abdel Aziz, A.(2), Mohammed. M, Samy

(1) Department OF Agricultural Sciences Institute of Environmental Studies and Research Ain Shams University, (2) Faculty of Agriculture Ain-Shams University (3) Department of Economic Studies, Desert Research Center

\begin{abstract}
The problem of research was the limitations of water resources with the growing water needs in agriculture. The research aimed at studying the estimation of the production and costs functions of the olive crop.Production functions show the extent to which agricultural production units achieve economic efficiency in their use of production resources involved in the production process and the extent to which these units maximize the profits of the agricultural product. The important indicators both at the level of the production unit and at the national level the relationship between costs and production, which can be used in the formulation and analysis of price policies and help agricultural producers in making their own productive decisions, which would encourage producers to continue or to expand the production process or stop production, as well as to determine the volume of production that maximizes profits and thus achieve economic efficiency of the use of productive elements.

The Results showed that to determine the parameters of the yield function of the olive yield from the data of the research sample according to the estimated model in the form of cup-Douglas, by introducing all the productive elements affecting the total output of the olive yield, (EP) for the function by about 0.51 for the total sample and $0.99,1.06$ and 1.02 for the three categories respectively. This shows that the production is in the first stage and the optimum production volume which reduces the costs of olive production in the total sample of the study was about 4.3 tons and the other three categories Reached 1.98 tons, 2.3 tons, 3.4 tons, respectively, And that the total actual farm size of the total sample was about 2.5 tons, which is less


J. Environ. Sci.

Institute of Environmental Studies and Research - Ain Shams University

than the optimal production volume and 2.2 tons, 2.3 tons, 3 tons, which is greater than the optimal production volume in the third category. As for the size of economic production, which maximizes profit, 4.9 tons in the total sample and in the other three categories reached 2 tons, 2.38 tons, 4.9 tons, respectively.

The research recommends to develop rain harvesting methods, introduction of modern supplementary irrigation techniques to increase the efficiency of supplementary irrigation, awareness of the importance of tillage operations to increase soil permeability so that it can absorb the largest amount of rainwater and store it in layers under the surface of the soil to benefit trees during the growing season, and caring for the human element to increase production and the level of economic efficiency of olives on farms.

Keywords: Cost and production functions - Economic efficiency - Optimized production volume - Progressive multiple regression. 